\title{
Radiographic and clinical outcomes following MIS-TLIF in patients with adult lumbar degenerative scoliosis
}

\author{
Yongfei Zhao ${ }^{1 \dagger}$, Yan Liang ${ }^{2 \dagger}$ and Keya Mao ${ }^{1 *}$
}

\begin{abstract}
Background: Patients suffering from adult lumbar degenerative scoliosis (ALDS) are commonly complicated with advanced age, osteoporosis, cardiopulmonary insufficiency, and some other medical comorbidity. Therefore, the traditional open surgery can lead to high rate of postoperative complications. The purposes of this study were to introduce our experiences and explore the efficacy and feasibility of minimally invasive transforaminal lumbar interbody fusion (MIS-TLIF) in the treatment of patients with ALDS.
\end{abstract}

Methods: From January 2008 to January 2014, a retrospective study of 22 patients with ALDS treated with MIS-TLIF was followed up at least 2 years. All patients suffered from one-level lumbar stenosis, and the nerve root block was performed to make sure the exact level. The clinical and radiographic outcomes were evaluated preoperatively and at the time of 2-year follow-up.

Results: The mean visual analog scale (VAS) back pain scores decreased from $6.2 \pm 1.8$ preoperatively to $2.2 \pm 0.7$ at 2-year follow-up $(P<0.05)$, and the mean VAS leg pain scores decreased from $8.2 \pm 0.7$ preoperatively to $1.4 \pm 1.4$ at 2 -year follow-up $(P<0.05)$. The Oswestry Disability Index score improved from $62.4 \pm 16.1 \%$ preoperatively to $24.2 \pm$ $9.3 \%$ at 2-year follow-up $(P<0.05)$. The average lumbar curve was $20.7^{\circ} \pm 7.0^{\circ}$ preoperatively and $12.7^{\circ} \pm 7.1^{\circ}$ at 2 -year follow-up $(P<0.05)$. The lumbar lordosis changed from $-39.5^{\circ} \pm 13.6^{\circ}$ to $-43.6^{\circ} \pm 10.6^{\circ}$ at 2 -year follow-up $(P<0.05)$. Solid fusion was achieved in all patients.

Conclusion: The technique of MIS-TLIF can be used to treat the patients with ALDS whose symptom is mainly from one-level lumbar stenosis, achieving favorable clinical outcomes and good fusion, with less blood loss and complications.

Keywords: MIS-TLIF, Adult lumbar degenerative scoliosis, Cobb angle, Visual analog scale, Oswestry disability index

\section{Background}

The adult lumbar degenerative scoliosis (ALDS), described as "de novo" scoliosis, was defined as a curve $>10^{\circ}$ due to degeneration of the facets and discs [1]. The patients of ALDS usually suffer from radicular or neurogenic claudication symptoms and back pain which make the surgery necessary [2-5]. However, the patients of ALDS are usually complicated with advanced age, osteoporosis, cardiopulmonary insufficiency, and other medical comorbidities, which contribute to the high rate of postoperative complications. Traditional open surgery has been associated

\footnotetext{
* Correspondence: maokeya301spine@163.com

${ }^{\dagger}$ Equal contributors

${ }^{1}$ The General Hospital of Chinese People's Liberation Army (301 hospital),

Beijing 100853, China

Full list of author information is available at the end of the article
}

with a major complication rate as high as $28-86 \%$ [6-8], and the risks of morbidity have been shown to increase with advancing age [9].

In order to lower the incidence of the complication, several minimally invasive methods of treatment for ALDS have been advocated [10-12]. However, the best option for this disorder is still controversial. The purposes of this study are to introduce our experience and explore the efficacy and feasibility of the technique of minimally invasive transforaminal lumbar interbody fusion (MISTLIF) for patients of ALDS whose symptom is mainly single-level radicular pain or neurogenic claudication, without dynamic back pain. 


\section{Methods}

\section{Patients}

From January 2008 to January 2014, 22 consecutive patients with ALDS, treated with MIS-TLIF in our hospital, were retrospectively analyzed. They were followed up at least 2 years. There were 8 males and 14 females, with an average age of 63.7 years (range 47-79 years). Inclusion criteria were (1) Cobb angle above $10^{\circ}$, (2) posterior-only procedure for adult scoliosis correction, (3) suffered from one-level lumbar stenosis and the nerve root block was performed to make sure the exact level, (4) treated with MIS-TLIF technique, (4) availability of radiographic examinations (full-length AP and lateral radiographs) and clinical data (inpatient medical records and questionnaire), (5) participated in non-operative therapies, including bracing, resting, physiotherapy, and analgesics, without adequate relief of their symptoms. Exclusion criteria were (1) idiopathic curves; (2) prior lumbar fusion surgery; (3) other comorbidities, such as neoplasia, trauma, and infection; (4) patients whose symptoms are mainly dynamic or fatigue back pain.

\section{Study measures}

Study measures were obtained through a review of inpatient medical records and questionnaire. The primary measures of this study were blood loss, surgery time, the time to ambulation, postoperative hospital stay, visual analog score (VAS), and Oswestry Disability Index (ODI).

\section{Radiologic assessment}

Radiographic examinations were performed preoperatively, postoperatively, and at the time of every follow-up. Radiographic data were collected and evaluated preoperatively and at the time of 2-year follow-up. The Cobb angle of the lumbar curve was measured using the standard Cobb's method on an anteroposterior radiograph, and the lumbar and pelvic parameters were measured on a lateral radiograph including lumbar lordosis (LL), sacrum slope (SS), and pelvic tilt (PT). The radiologic films and CT taken at 2-year follow-up were utilized to assess fusion. The fusion criteria were based on Bridwell interbody fusion grading system (Table 1), and the assessments were performed by two independent assessors.

Table 1 Bridwell interbody fusion grading system

\begin{tabular}{ll}
\hline Grade & Description \\
\hline II & Fused with remodeling and trabeculae are present \\
Graft intact, not fully remodeled and incorporated, but \\
no lucency is present \\
Graft intact, potential lucency is present at the top and \\
bottom of the graft \\
Fusion is absent with collapse/resorption of the graft
\end{tabular}

\section{Surgical procedures}

All cases were treated with nerve root block to make sure the level where the pain comes from. The nerve root block was performed under the $\mathrm{C}$-arm fluoroscopy. The puncture needle entered the foramen intervertebrale in a proper entry point and angle. And the lidocaine was used to block the nerve root. Then, the MIS-TLIF surgery was performed.

Under general anesthesia, the patient was placed in a prone position on the operating table. The needle is used to position the level under the $\mathrm{C}$-arm fluoroscopy. A $2.5-\mathrm{cm}$ incision away from the center line $2 \mathrm{~cm}$ was made, and a tubular retractor was placed in a proper angle. Then, the trajectory of pedicle screw was prepared bare-handed and sealed by bone wax. The isthmus, the posterior arch of the vertebrae, the inferior joint facet, and the ligamentum flavum were resected. These local bones were kept for autograft during the interbody fusion. The nerve root was identified, and the canal of nerve root was clearly decompressed. Then, discectomy and endplate preparation were performed, and the disc space was packed with the autograft bones. A cage interbody graft was then inserted and commonly placed relatively to the concave side to restore lumbar lordosis and decrease lumbar curve. Another $2.5-\mathrm{cm}$ incision was made on the contralateral side, and the same procedure of instrumentation and decompression was performed. The lumbar pedicle screws were inserted bilaterally, and the progress of compression on the convex side and distraction on the concave side was performed. Finally, the incision was sewn up without drainage (Fig. 1).

\section{Statistical analysis}

Data were expressed as mean \pm standard deviations for variables. Preoperative and postoperative differences were performed using a paired $t$ test, and statistical significance was set at $P<0.05$. All analyses were carried out using the SPSS (Statistical Package for the Social Sciences) version 17.

\section{Results}

\section{Surgical results}

The average surgical time was $153.3 \pm 26.3 \mathrm{~min}$ (range 105-220 min) with a mean intraoperative blood loss of $175.0 \pm 83.4 \mathrm{ml}$ (range 50-325 ml). The hospital stay was $5.4 \pm 0.9$ days (range $4-7$ days). The time to ambulation was $2.5 \pm 0.9$ days (range $1-4$ days) postoperatively (Table 2).

\section{Clinical results}

The mean VAS back pain scores decreased from $6.2 \pm 1.8$ preoperatively to $2.2 \pm 0.7$ at 2 -year follow-up $(P<0.05)$, and the mean VAS leg pain scores decreased from $8.2 \pm 0.7$ preoperatively to $1.4 \pm 1.4$ at 2 -year follow-up $(P<0.05)$. 

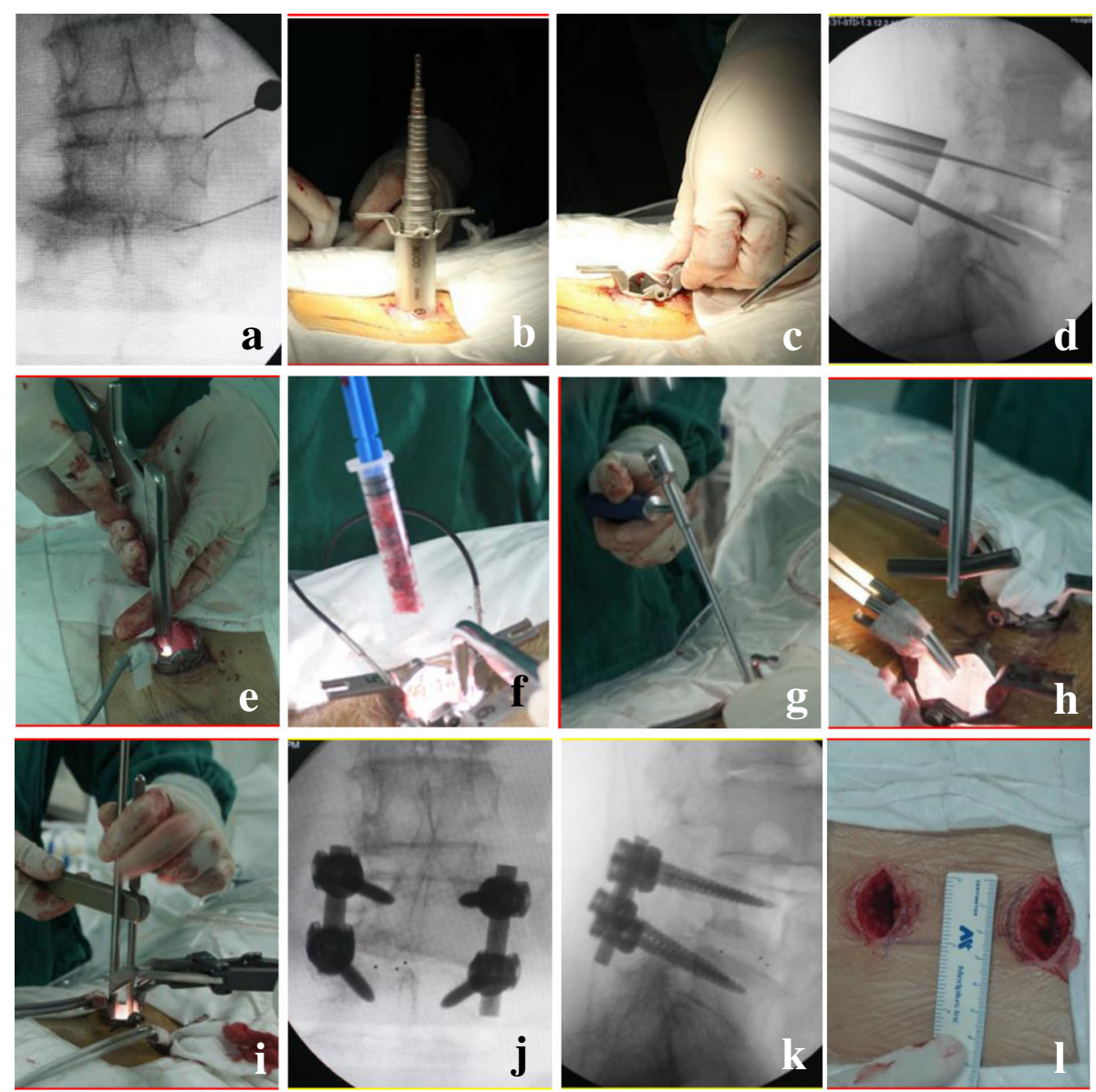

Fig. 1 The MIS-TLIF technique. a Position the level under the C-arm fluoroscopy. b, c The tubular retractor was placed. $\mathbf{d}$ The road of pedicle screw was prepared. e The progress of decompression was performed. $\mathbf{f}, \mathbf{g}$ Bone and cage interbody graft was inserted. $\mathbf{h}$, $\mathbf{i}$ : The progress of compression was performed. $\mathbf{j}$, k The postoperative X-ray showed good result. I The incision was about $2.5 \mathrm{~cm}$

Table 2 Patient demographics and operative data

\begin{tabular}{ll}
\hline Variables & Data \\
\hline Age (years) & 63.7 \\
Sex & \\
$\quad$ Male & 8 \\
$\quad$ Female & 14 \\
Level & \\
$\quad$ L3/L4 & 3 \\
L4/L5 & 11 \\
L5/S1 & 8 \\
Surgery time (min) & $153.3 \pm 26.3$ \\
Blood loss (ml) & $175.0 \pm 83.4$ \\
Time to ambulation (days) & $2.5 \pm 0.9$ \\
Hospital stay (days) & $5.4 \pm 0.9$ \\
\hline
\end{tabular}

The ODI score improved from $62.4 \pm 16.1 \%$ preoperatively to $24.2 \pm 9.3 \%$ at 2 -year follow-up $(P<0.05)$. All patients were satisfied with the surgical results (Table 3).

\section{Radiological results}

The levels of surgery were L3/4 in 3 cases (13.6\%), L4/5 in 11 cases $(50 \%)$, and L5/S1 in 8 cases (36.4\%). The mean Cobb angle decreased from $20.7^{\circ} \pm 7.0^{\circ}$ preoperatively to $12.7^{\circ} \pm 7.1^{\circ}$ at 2 -year follow-up with a mean correction of $8^{\circ}(P<0.05)$. The lumbar lordosis changed from $-39.5^{\circ} \pm$ $13.6^{\circ}$ preoperatively to $-43.6^{\circ} \pm 10.6^{\circ}$ at 2 -year follow-up $(P<0.05)$. The pelvic tilt decreased from $20.2^{\circ} \pm 5.5^{\circ}$ preoperatively $14.9^{\circ} \pm 6.4^{\circ}$ to at 2 -year follow-up $(P<0.05)$. The sacrum slope changed from $28.5^{\circ} \pm 9.1^{\circ}$ preoperatively to $33.5^{\circ} \pm 6.1^{\circ}$ at 2 -year follow-up $(P<0.05)$. All patients achieved grade 1 fusion at the final follow-up according to radiological evidence, and no obvious loss of correction occurred (Table 3) (Fig. 2). 
Table 3 Radiographic and clinical outcomes in 16 patients

\begin{tabular}{llllc}
\hline Variables & Preoperative & $\begin{array}{l}\text { 2-year postoperative } \\
\text { follow-up }\end{array}$ & $t$ & $P$ \\
\hline Cobb & $20.7^{\circ} \pm 7.0^{\circ}$ & $12.7^{\circ} \pm 7.1^{\circ}$ & 8.5 & $0.000<0.05$ \\
LL & $-39.5^{\circ} \pm 13.6^{\circ}$ & $-43.6^{\circ} \pm 10.6^{\circ}$ & 3.5 & $0.014<0.05$ \\
SS & $28.5^{\circ} \pm 9.1^{\circ}$ & $33.5^{\circ} \pm 6.1^{\circ}$ & -3.8 & $0.006<0.05$ \\
PT & $20.2^{\circ} \pm 5.5^{\circ}$ & $14.9^{\circ} \pm 6.4^{\circ}$ & 3.5 & $0.019<0.05$ \\
VAS(back) & $6.2 \pm 1.8$ & $2.2 \pm 0.7$ & 6.2 & $0.000<0.05$ \\
VAS(leg) & $8.2 \pm 0.7$ & $1.4 \pm 1.4$ & 12.9 & $0.000<0.05$ \\
ODI(\%) & $62.4 \pm 16.1$ & $24.2 \pm 9.3$ & 8.1 & $0.000<0.05$ \\
\hline
\end{tabular}

\section{Complication}

There was one dura tear with cerebrospinal fluid leakage, which was repaired during operation. One patient suffered from pneumonia and recovered after antibiotic treatment. One patient developed the adjacent segment degeneration which will need another surgery. There was no complication of neurologic injury, wound infection, or non-union. There had been no breakage or failure of any screw or rod.

\section{Discussion}

The ALDS is usually caused by the degeneration of the spine. The prevalence of ALDS is reported to be $6 \%$ [13-16]. The treatment of the ALDS is in an ongoing debate [17-19]. In order to choose the best option, the Lenke-Silva [1] classification is described to instruct the treatment. The open surgery to correct deformity, which can get good coronal and sagittal balance, is becoming popular. However, for the patients with ALDS, the average age is in the 60s [20]. The advanced age of the patient is often complicated with medical comorbidities, which will add additional challenges to the surgery and increase the complication rate of the patient. According to the literature, the traditional open surgery has been associated with a major complication rate as high as $28-86 \%$ [21], and the
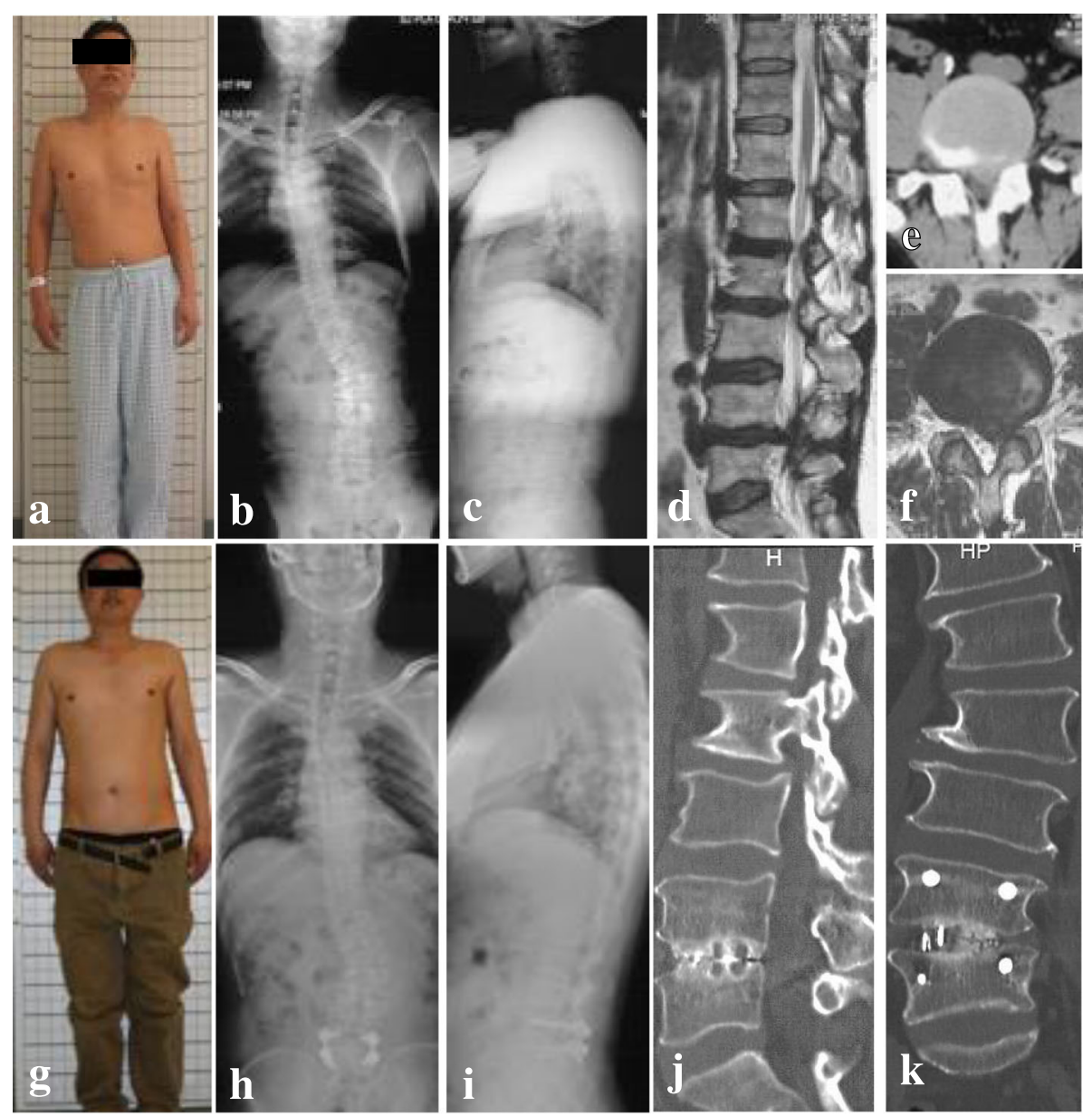

Fig. 2 A 65-year-old male patient suffering from adult lumbar degenerative scoliosis. The main complains were severe back and left leg pain complicated with intermittent claudication. a Preoperative view photograph showed that the trunk tilt to the left is obvious. b, c Preoperative X-ray showed the Cobb angle was $32^{\circ}$, and the coronal was imbalanced. $\mathbf{d}, \mathbf{e}, \mathbf{f}$ Preoperative CT and MRI showed the L4/5 disc herniation. $\mathbf{g}$ The view photograph of the 2-year follow-up showed that the trunk tilt is not obvious. $\mathbf{h}, \mathbf{i}$ The $\mathbf{X}$-ray of the 2-year follow-up showed the Cobb angle was $23^{\circ}$, and the coronal was balanced. $\mathbf{j}, \mathbf{k}$ The CT of the 2-year follow-up showed grade 1 fusion 
risks of morbidity have been shown to increase with advancing age [22].

To combat these challenges, the minimally invasive surgeries have been developed for the treatment of ALDS [23-25]. The minimally invasive spinal surgery can reduce intraoperative blood loss, lower infection rates, and quicker mobilization, which will be highly desired in the adult lumbar degenerative scoliosis population [26]. Rosen's study [27] proved that patients older than 75 with significant medical comorbidities underwent minimally invasive spinal surgery for spinal canal decompression could be efficient and safe. The minimally invasive surgical treatment of ALDS is increasingly being recognized as safe and effective.

The technique of MIS-TLIF was first described by Foley [28], using tubular retractors under radiological guidance by a muscle-dilating approach, which can reduce the amount of iatrogenic muscle and soft tissue injuries, which was confirmed by many other surgeons [29-31]. Lee [32] found that the MIS-TLIF surgery generally has minimal blood loss compared with the open surgery, and the patients treated by open surgery generally take three times as long to start walking, and they stay twice as long in the hospital.

ALDS patients typically present with symptoms of low back pain, lower back fatigue, neurogenic claudication, lumbosacral radicular pain, and a progressive deformity. The golden standard treatments are decompression, fusion, and deformity correction [17, 23]. However, the patients with ALDS have different clinical manifestations, which need various surgical principles and techniques. Therefore, we advocated the precise treatment for these patients, to solve the symptom rather than restore the alignment. The surgery should be as minor as possible to reduce the complications. The nerve root block is a necessary procedure for precise treatment, which can make sure the level where the pain comes from. In our study, 22 patients with ALDS whose symptom is mainly single-level radicular pain or neurogenic claudication were treated with the technique of MIS-TLIF and achieve a good decompression, instrumentation, and fusion with less injury, relieving patients' pain, and gaining satisfactory clinical outcome eventually. From the data, for the patients with ALDS who suffered from one-level lumbar stenosis, the technique of MIS-TLIF can be accomplished within shorter operative time, to be associated with much less blood loss and shorter hospital stays [1, 13], which result in considerably less patient morbidity, less cost, and earlier rehabilitation.

Besides, the deformity correction is another important consideration. In our study, the mean Cobb angle decreased from $20.7^{\circ} \pm 7.0^{\circ}$ to $12.7^{\circ} \pm 7.1^{\circ}$ with a mean correction of $8^{\circ}$. And the lumbar lordosis changed from $-39.5^{\circ} \pm$ $13.6^{\circ}$ to $-43.6^{\circ} \pm 10.6^{\circ}$. With a thorough decompression, disc removement, interbody bone graft and cage instrument, compression on the convex side and distraction on the concave side, and the local deformity could be corrected to some degree. During the surgery, we commonly use a large cage placed relatively to the concave side to restore lumbar lordosis and decrease lumbar curve. Besides, the painful stimulus caused by disc herniation or stenosis is removed; the nerve root, muscle, and ligament are relaxed which are helpful for deformity correction. The change of the parameters demonstrated that the technique of MIS-TLIF could improve the balance of the patients to some degree. Earlier studies have shown a significant positive correlation between the radiographic results and clinical outcomes in the surgical treatment of ALDS, which is in accordance with our study $[14,33]$. But the deformity of patients in our study is still there, and the outcome of deformity correction is not satisfied. Therefore, the long-term evaluation should be future studied.

There are limitations in this study. Firstly, due to the steep learning curve of MIS-TLIF and the characteristic of the ALDS patients, it may be difficult for junior surgeons to do the procedure, which could result in increased surgical time and blood loss and more complications such as dura tear and nerve root injury. All the procedures in this study were accomplished by the corresponding author, an experienced senior surgeon of MIS-TLIF. Secondly, the patients with ALDS present many different symptoms. Right now, the technique of MIS-TLIF is only suitable for patients whose symptom is mainly single-level radicular pain or neurogenic claudication. The indication of MIS-TLIF for ALDS is relatively narrow. Besides, the number of the cases in our study is relatively small, and the time of follow-up is relatively short, so the larger cases of long-term observation research should be future studied.

\section{Conclusion}

In conclusion, for the patients with ALDS, the deformity correction is not that necessary for some patients; we advocated the precise treatment to relieve the main pain and improve the symptom. For the patients with ALDS who suffered from one-level lumbar stenosis, the technique of MIS-TLIF was safe and effective. The technique of MIS-TLIF is generally associated with less blood loss and pain, earlier ambulation and discharge from hospital, and reduced incidence of the complications. Although the technique is not suitable for all patients with ALDS, it may be a suitable option for some patients.

\section{Abbreviations}

ALDS: Adult lumbar degenerative scoliosis; LL: Lumbar lordosis; ODI: Oswestry Disability Index; PT: Pelvic tilt; SS: Sacrum slope; VAS: Visual analog score

\section{Acknowledgements}

We acknowledge Yonggang Zhang who contributed towards the study by making substantial contributions to the design and acquisition of data. 


\section{Funding}

The authors declare that they have no funding

\section{Availability of data and materials}

Please contact the author for data requests.

\section{Authors' contributions}

YZ carried out the molecular genetic studies, participated in the sequence alignment, and drafted the manuscript. $Y L$ participated in the design of the study and performed the statistical analysis. KM conceived the study, participated in its design and coordination, and helped to draft the manuscript. All authors read and approved the final manuscript.

\section{Ethics approval and consent to participate}

This retrospective study was approved by the Institutional Review Board (IRB) of 301 and Peking University People's hospitals. All patients involved in the study consented to participate in the study, and the written consent has been obtained from all the patients.

\section{Consent for publication}

All individual persons consented to publish their data.

\section{Competing interests}

The authors declare that they have no competing interests.

\section{Publisher's Note}

Springer Nature remains neutral with regard to jurisdictional claims in published maps and institutional affiliations.

\section{Author details}

${ }^{1}$ The General Hospital of Chinese People's Liberation Army (301 hospital), Beijing 100853, China. 'Peking University People's Hospital, Beijing 100044 , 314, China.

Received: 27 December 2017 Accepted: 13 March 2018 Published online: 19 April 2018

\section{References}

1. Silva FE, Lenke LG. Adult lumbar degenerative scoliosis: evaluation and management. Neurosurg Focus. 2010;28(3):E1.

2. Cheh G, Bridwell K, Lenke L, et al. Adjacent segment disease following lumbar/thoracolumbar fusion with pedicle screw instrumentation: a minimum 5-year follow-up. Spine. 2007;32:2253-7.

3. Cho K, Suk S, Park S, et al. Complications in posterior fusion and instrumentationfor degenerative lumbar scoliosis. Spine. 2007;32:2232-7.

4. Crandall D, Morrison M, Baker D, et al. Direct vertebral translation to correct adult scoliosis. Spine J. 2005;5:118S.

5. Crandall D, Morrison M, Baker D, et al. Adult scoliosis correction: clinical and radiographic comparison of techniques. Spine J. 2006;6:S150-1.

6. Aebi M. The adult scoliosis. Eur Spine J. 2005:14:925-48.

7. Boachie-Adjei O, Dendrinos GK, Ogilvie JW, Bradford DS. Management of adult spinal deformity with combined anterior-posterior arthrodesis and Luque-Galveston instrumentation. J Spinal Disord. 1991;4:131-41.

8. Winter RB, Denis F, Lonstein JE, Dezen E. Salvage and reconstructive surgery for spinal deformity using Cotrel-Dubousset instrumentation. Spine. 1991; 16(8 Suppl):S412-7.

9. Zheng F, Cammisa FP Jr, Sandhu HS, Girardi FP, Khan SN. Factors predicting hospital stay, operative time, blood loss, and transfusion in patients undergoing revision posterior lumbar spine decompression, fusion, and segmental instrumentation. Spine. 2002;27:818-24.

10. Dickerman RD, East JW, Winters K, Tackett J, Hajovsky-Pietla A. Anterior and posterior lumbar interbody fusion with percutaneous pedicle screws: comparison to muscle damage and minimally invasive techniques. Spine. 2009;34:E923-5.

11. Mummaneni PV, Tu TH, Ziewacz JE, Akinbo OC, Deviren V, Mundis GM. The role of minimally invasive techniques in the treatment of adult spinal deformity. Neurosurg Clin North Am. 2013:24:231-48.

12. Smith WD, Christian G, Serrano S, Malone KT. A comparison of perioperative charges and outcome between open and mini-open approaches for anterior lumbar discectomy and fusion. J Clin Neurosci. 2012;19:673-80.

13. Vanderpool DW, James Jl, Wynne-Davies R. Scoliosis in the elderly. J Bone Joint Surg. 1969;51A(3):446-55.
14. Aebi M. Correction of degenerative scoliosis of the lumbar spine. A preliminary report. Clin Orthop Relat Res. 1988:232:80-6.

15. Swank $\mathrm{S}$, Lonstein JE, Moe JH, et al. Surgical treatment of adult scoliosis. A review of two hundred and twenty-two cases. J Bone Joint Surg. 1981;63:268-87.

16. Kobayashi T, Atsuta Y, Takemitsu M, Matsuno T, Takeda N. A prospective study of de novo scoliosis in a community based cohort. Spine. 2006;31:178-82

17. Tribus C. Degenerative lumbar scoliosis: evaluation and treatment. J Am Acad Orthop Surg. 2003;11:174-83.

18. Daffner SD, Vaccaro AR. Adult degenerative lumbar scoliosis. Am J Orthop. 2003;32:77-82. discussion 82

19. Tribus CB. Degenerative lumbar scoliosis: evaluation and management. J Am Acad Orthop Surg. 2003;11:174-83.

20. Pritchett JW, Bortel DT. Degenerative symptomatic lumbar scoliosis. Spine. 1993;18(6):700-3.

21. Allon T, Smith JS, Shaffrey Cl, Lenke LG, Brodke D. Degenerative Spinal Ddformity. Neurosurgery. 2015;77(Suppl 4):S75-91.

22. Zheng F, Cammisa FP Jr, Sandhu HS, Girardi FP, Khan SN. Factors predicting hospital stay, operative time, blood loss, and transfusion in patients undergoing revision posterior lumbar soine decompression, fusion, and segmenta instrumentation. Spine. 2002;27(8):818-24.

23. Anand N, Baron EM, Thaiyananthan G, Khalsa K, Goldstein TB. Minimally invasive multilevel percutaneous correction and fusion for adult lumbar degenerative scoliosis:a technique and feasibility study. Journal of Spinal Disorders and Techniques. 2008:21(7):459-67.

24. Scheufler KM, Cyron D, Dohmen H, Eckardt A. Less invasive surgical correction of adult degenerative scoliosis, part I: technique and radiographic results. Neurosurgery. 2010;67(3):696-710.

25. Wang MY, Mummaneni PV. Minimally invasive surgery for thoracolumbar spinal deformity: initial clinical experience with clinical and radiographic outcomes. Neurosurg Focus. 2010;28(3):1-8.

26. Schwender JD, Holly LT, Rouben DP, Foley KT. Minimally invasive transforaminal lumbar interbody fusion (TLIF): technical feasibility and initial results. Journal of Spinal Disorders and Techniques. 2005;18(1):S1-6.

27. Rosen DS, OToole JE, Eichholz KM, Hrubes M, Huo D, Sandhu FA, et al. Minimally invasive lumbar spinal decompression in the elderly: outcomes of 50 patients aged 75 years and older. Neurosurgery. 2007;60:503-10.

28. Foley KT, Holly LT, Schwender JD. Minimally invasive lumbar fusion. Spine. 2003;15(suppl):26-35.

29. Schwender JD, Holly LT, Rouben DP, et al. Minimally invasive transforaminal lumbar interbody fusion (TLIF): technical feasibility and initial results. J Spinal Disord Tech. 2005;18:S1-6.

30. Peng CW, Yue WM, Poh SY, et al. Clinical and radiological outcomes of minimally invasive versus open transforaminal lumbar interbody fusion. Spine. 2009:34:1385-9.

31. Villavicencio AT, Burneikiene $\mathrm{S}$, Roeca CM, et al. Minimally invasive versus open transforaminal lumbar interbody fusion. Surg Neurol Int. 2010;31(1):12

32. Lee $\mathrm{KH}$, Yue WM, et al. Clinical and radiological outcomes of open versus minimally invasive transforaminal lumbar interbody fusion. Eur Spine J. 2012 Nov;21(11):2265-70

33. Hioki A, Miyamoto $\mathrm{K}$, Kodama $\mathrm{H}$, et al. Two-level posterior lumbar interbody fusion for degenerative disc disease: improved clinical outcome with restoration of lumbar lordosis. Spine J. 2005;5:600-7.

\section{Submit your next manuscript to BioMed Central and we will help you at every step:}

- We accept pre-submission inquiries

- Our selector tool helps you to find the most relevant journal

- We provide round the clock customer support

- Convenient online submission

- Thorough peer review

- Inclusion in PubMed and all major indexing services

- Maximum visibility for your research

Submit your manuscript at www.biomedcentral.com/submit

Biomed Central 